\title{
Fluorimetric Determination of Dichloroacetamide by RPLC with Postcolumn Detection
}

\author{
Yong-Wook Choi and David A. Reckhow ${ }^{\dagger}$ \\ School of Natural Science. Jeonju Cniversitw, Jeonju $560-759$, Korea \\ -Department of Civil and Enwironmental Engineering. Chiversitv of Massachusetts at Amherst. Amherst, MLA O1003, USt \\ Received Aprit 12, 2004
}

\begin{abstract}
An RPLC-postcolumn detection method has been developed for the fluorimetric determination of dichloroacetamide (DCAD) in water. After ammonia and $\mathrm{DCAD}$ were separated on a $\mathrm{C}_{1} \&$ nonpolar stationary phase with $2.5 \%$ methanol- $0.02 \mathrm{M}$ phosphate buffer at $\mathrm{pH} 3$, the column eluant was reacted with post column reagents. $o$-phthaldialdehỵde (OPA) and sulfite ion at $\mathrm{pH} 11.5$. to produce a highly fluorescent isoindole fluorophore. which was measured with a fluorescence detector $\left(\lambda_{\mathrm{ex}}=363 \mathrm{~nm}, \lambda_{\mathrm{en}}=425 \mathrm{~nm}\right)$. With the optimized conditions for RPLC and the postcolumn derivatization. the calibration curve was found to be linear in the concentration ranges of 0.5 and $20 \mu \mathrm{M}$ for $\mathrm{DCAD}$. and the detection limit for DCAD was $0.18 \mu \mathrm{M}(23$ $\mu \mathrm{g} / \mathrm{L}$ ). This corresponded to $18 \mathrm{pmol}$ per $100 \mu \mathrm{L}$ injection volume for a signal-to-noise ratio of 3 , and the repeatability and reproducibility of this method were $1.0 \%$ and $2.5 \%$ for five replicate analyzes of $2 \mu \mathrm{M}$ $\mathrm{DCAD}$. respectively: The degradation yields DCAD to ammonia were 94 and $99 \%$ and the percent recoveries of DCAD from + and $6 \mu \mathrm{M} \mathrm{DCAD-spiked} \mathrm{tap} \mathrm{water} \mathrm{were} \mathrm{shown} \mathrm{mean} \mathrm{more} \mathrm{than} 97 \%$.
\end{abstract}

Key Words : Ammonia, Dichloroacetamide (DCAD), RPLC-postcolunn detection. OPA

\section{Introduction}

The chlorination of drinking water results in the forntation of a variety of disinfection byproducts (DBPs) by reaction with algae. natural organic matter (NOM) or artificial organic contaminants. The most common DBPs are trihalomethanes (THMs). haloacetic acids (HAAs), haloacetonitriles (HANs), haloketones (HKs), and halopicrines (HPs). ${ }^{1-6}$ Of these DBPs, dichloroacetic acid (DCAA) has been classified by the U.S. EPA as probable carcinogen for humans (group B2). while trichloroacetic acid (TCAA) was considered a possible carcinogen (group C). ${ }^{7.8}$ Trehy and Bieber reported that dichloroacetonitrile (DCAN). dibromoacetonitrile (DBAN). and bromochloroacetonitrile $(\mathrm{BC} A N)$ are found in South Florida drinking water a concentration up to $42 \mu \mathrm{g} / \mathrm{L}$. Oliver ${ }^{10}$ reported that dihaloacetonitriles (DHANs) in southern Ontario drinking water were present at approximately $10 \%$ of THMs concentration. In Korea. a maxinum contaninant level (MCL) of $0.10 \mathrm{mg} / \mathrm{L}$ was established for total trihalromethanes (TTHMs). More recently, the Ministry of Environment (MOE) in Korea has established an MCL of $0.10 \mathrm{mg} / \mathrm{L}$ for HAAs in water treatment plants producing more than 100 thousand tons from 2003. and in addition. the HANs such as DCAN, TCAN, DBAN and chloral hydrate have been newly regulated in the driuking water guideline. Much research has been reported on the occurrence and contamination level of DBPs in Korea. ${ }^{1-16}$ THMs and HANs were found to be produced by chlorination of amino acids, while the ratio of the formed nitriles to the formed aldehydes was influenced by reaction conditions. ${ }^{17}$ The final products of HANs have

\footnotetext{
${ }^{*}$ Corresponding Author. e-mail: cyw4l laj achr
}

been shown to be HAAs. and where dichloroacetamide (DCAD) has been reported to be produced as an intermediate on the way to forming DCAA ${ }^{18}$ The $p K_{4}$ of DCAD and trichloroacetamide (TCAD) is known to be 13.55 and 12.42 at $25^{\circ} \mathrm{C}$. respectively. ${ }^{19}$ Both are known to be hydrolysed to produce ammonia in alkaline solution at $\mathrm{pHs}$ ranging from 9 to $12 .^{20}$ In general, the determination of HANs could be conducted using a liquid-liquid extraction followed by gas cluromatograph-electron capture detector (GC-ECD) according to U.S. EPA method 551.1, " while the determination of HAAs including DCAA and TCAA can be carried out by methylation with diazomethane according to U.S. EPA method 552.22 or by methylation with acidic methanol as described in the U.S. EPA method 552.1 $1^{23}$ or $552.2^{24}$ followed by GC-ECD through extraction with methyltertiary butylether (MTBE). Recently. Ko et al. determined HAAs by ion chromatography. Kelty extracted HAAs with MTBE followed by derivatization with perfluorohaptanoic acid and analyzed those by GC-ECD, and the detection limits were from 0.003 to 0.07 $\mu \mathrm{g} / \mathrm{L}$ But few analytical methods for DCAD or TCAD have been reported. Richardson ${ }^{27}$ measured TCAD in drinking water by using GC with mass spectrometry (MS). and Rapp and Reckhow ${ }^{28}$ measured DCAD and TCAD by the same method as that used for the HANs. The determination of DCAA by U.S. EPA method 552.2 in the presence of DCAD could result in the displacement of DCAD concentration toward the DCAA concentration. with a resulting positive error in the deternination of DCAA. ${ }^{28}$ Therefore. a selective analytical method for DCAD is needed. The DCAD has an anide group, so that an approach aimed at both the carbonyl and amine group could be successful. if appropriate derivatizing reagents are employed. An attempt 
to use 2,4-dinitrophenylhydrazine (DNPH) or o-phthaldialdehyde (OPA)/mercaptoethanol (MF) to derivatize amide group indicated no reaction was occurring during the preliminary experiment.

The purpose of this work was to explore and define optimal chromatographic conditions in a single run with a mixture of ammonia and DCAD by means of fluorescence detection after postcolumn derivatization. In addition, we also propose to establish optimal derivatization conditions in determining DCAD by reversed phase liquid chromatography (RPI C)-postcolumn detection.

\section{Experimental Section}

Chemicals. The separation column $(3.9 \times 150 \mathrm{~mm})$ and guard column $(3.9 \times 22 \mathrm{~mm})$ of Nova-Pak $(5 \mu \mathrm{m}$. Waters) were purchased from Waters (Yongwha Co.. Korea). 2,2dichloroacetamide (DCAD, 98\%), sodium hydrogenphosphate $(99+\%)$, phosphoric acid $(85 \%)$, phthalic dicarboxaldehyde (OPA, 97\%), sodium sulfite $(98+\%)$, and mercaptoethanol (MГ., 98\%) were obtained from Aldrich Chemical Company and used without further purification. Reagent grade ammonium chloride was obtained from Yakuri (Osaka, Japan), and sodium phosphate dodecahydrate (GR) were obtained from Shinyo pure chemical (Osaka, Japan), potassium hydroxide (GR), sodium hydroxide (GR) were obtained from Aldrich. HPLC grade methanol was purchased from Fisher.

Preparation of standard and reagent solutions. Stock solution of ammonia and DCAD (100 mmol/L, each), were prepared in Milli-Q water, and then diluted to the desired concentration (standard solutions) with Milli-Q water. One molar $\mathrm{KOH}$ and $1 \mathrm{M} \mathrm{NaOH}$ stocks were prepared by diluting the reagent with Mill-Q water. The OPA solution was prepared by diluting $20 \mathrm{mmol}$ of OPA dissolved in 100 $\mathrm{ml}$. of methanol to $1 \mathrm{~L}$, with Milli-Q water. The buffer solution was prepared just before use, and it contained $0.1 \mathrm{M}$ sodium phosphate with $15 \mathrm{mM}$ of sulfite.

RPLC system and apparatus. The RPLC system con-

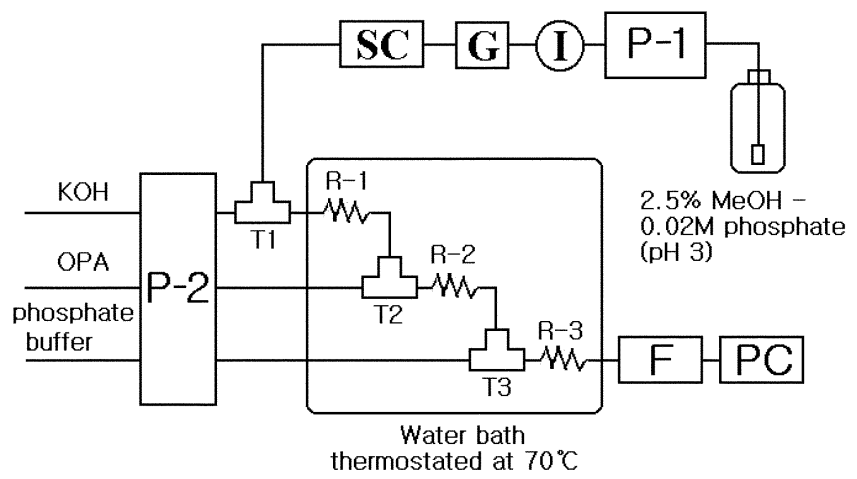

Figure 1. Schematic diagram of RPLC-postcolumn detection for determination of I)CAI). P-I: high pressure punp. I. injector (100) $\mu L)$; $G$. guard column: $S C$. Novit-Pak $C_{18}$ separation column; $\mathrm{P}-2$. peristaltic pump: T. mixing tes: R. reaction coil; F. tluorescence detector. $\lambda_{\mathrm{ex}} 363 \mathrm{~nm}$. $\lambda_{\mathrm{em}} 425 \mathrm{~nm}$. sisted of a M930 solvent delivery pump, SDV 30 Plus solvent degassor and valve moldule, a Rheodyne M7125i syringe-loading sample injector ( $100 \mu \mathrm{l}$. loop), an RF-530 fluorescence detector (Shimadzu), and an Autochro-2000 data acquisition module (Young-l.in, Seoul, Korea). The flow diagram for the RPL.C-postcolumn derivatization reaction of ammonia and DCAD is shown in Figure 1. Tubing used for the reaction was made of PTFF $(0.5 \mathrm{~mm}$ I.D. $\times 1$ / 16 in O.D.). Other tubing except the reaction tubing was made of stainless steel $(0.009$ in l,D. $\times 1 / 16$ in O.D.). A Minipuls 3 peristaltic pump for four channels was used to supply three kinds of reagent solutions. The postcolumn derivatization reaction was performed in a PTFE coil for hydrolysis, mixing and derivatization, which was immersed in a water bath thermostated at $70^{\circ} \mathrm{C}$.

The column outlet was connected to a three-way tee to be mixed with $0.05 \mathrm{M} \mathrm{KOH}$, delivered at flow rate of $0.5 \mathrm{ml}$ / min with the four channel peristaltic pump. The outlet of the tee was connected to the second three-way tee thereby introducing the $15 \mathrm{mM} \mathrm{OPA}$ reagent. The mixture of the eluate, $\mathrm{KOH}$ and OPA were mixed in the third three-way tee with $0.1 \mathrm{M}$ phosphate buffer containing $15 \mathrm{mM}$ sulfite $\langle\mathrm{pH}$ 11.5 delivered at the same flow rate as the $\mathrm{KOH}$ and $\mathrm{OPA}$ reagents). The outlet of the third tee was connected to a reaction coil of $6 \mathrm{~m}$ and its end was introduced to a quartz. flow cell in a fluorescence detector equipped with a Xenon lamp. The fluorescence intensity was acquired with Autochro-2000 data acquisition system.

\section{Results and Discussion}

Preliminary studies for determining DCAD. Roth suggested a method for primary amines and ammonia using OPA/mercaptoethanol (MГ) in a borate buffer at $\mathrm{pH}$ 9-10. This produces isoindole which is quantified by fluorescence detection. ${ }^{29}$ Ammonia showed about 20 or 30 times lower fluorescence intensity than those of primary amines for the $\mathrm{OPA} / \mathrm{M}$ : derivatization reaction. A positive error might be produced in determination for mixture of primary amine and ammonia by flow injection analysis (FIA) because the $\mathrm{HIA}$ could not differentiate between them. Thus. Genfa ${ }^{30}$ et al. described a selective FIA method for the determination of ammonia by use of OPA/sulfite in place of OPA/ME as a derivatizing reagent. This produces a signal that is 20 to 100 times higher in intensity compared to that of primary amine. We reported the determination of ammonia in drinking water and stream water based on the ammonia/Ol'A/sulfite ${ }^{31}$ and naphthalene-2,3-dicarboxaldehyde (NDA)/sulfite ${ }^{32}$ derivatives by using a home made FlA manifold. In our study, we wished to either directly measure DCAD through its OPA derivative using a UV-VIS spectrophotometer at $363 \mathrm{~nm}$ (the maximum absorption wavelength of ammonia/OPA/sulfite derivative) or to indirectly measure it via the OPA derivative of ammonia following hydrolysis of DCAD. To examine these possibilities, the variation of absorbance for $\mathrm{DCAD}$ / $\mathrm{OPA} / \mathrm{ME}$ or DCAD/OPA/sulfite derivatives with $\mathrm{pH}$ using two different nucleophiles, $\mathrm{ME}$ and sulfite for derivative was 
observed across a range in $\mathrm{pH}$ from $1-12$ (in universal buffer $^{3.3}$ over the range from $\mathrm{pH} 2$ to 12 , and in $0.1 \mathrm{M} \mathrm{HCl}$ $\mathrm{pH}$ 1). Although DCAD has a primary amine group, no absorbance following DCAD/OPA/ME or DCAD/OPA/ sulfite derivatization in the range of $\mathrm{pH} 9-10$ (the optimal reaction condition between OPA and amino acids) was observed. However, the preliminary test showed that the absorbance was dramatically increased below $\mathrm{pH} \mathrm{l}$ or above $\mathrm{pH}$ 12. That was because DCAD was supposed to hydrolyze into $\mathrm{NH}_{4}{ }^{-}$or $\mathrm{NH}_{3}$ in the presence of strong acid or strong base and to react with OPA. An FIA device for the determination of DCAD by hydrolysis and formation of $\mathrm{NH} / \mathrm{OPA} / \mathrm{sulfite}$ derivatives was developed, but it was difficult to distinguish the signal produced by DCAD and that produced by ambient ammonia. Therefore, in our study, we chose to separate DCAD from free ammonia by RPI.C. prior to hydrolysis and derivatization. This required that we identify optimal conditions for measuring $\mathrm{NH}_{3} / \mathrm{OPA} /$ sulfite derivatives with fluorescence detection after separation by RPI .C (e.g., postcolumn derivatization reaction). To find out if hydrolysis depends on a type of base, the preliminary studies indicated that using $\mathrm{KOH}$ showed higher tluorescence intensity than using $\mathrm{NaOH}$ for hydrolysis of DCAD. As shown in Figure 1, the optimum conditions of $\mathrm{KOH}$ concentration and reaction coil length for $\mathrm{KOH}$, reaction temperature, OPA concentration and reaction coil length for $O P A$, sulfite concentration and reaction coil length for
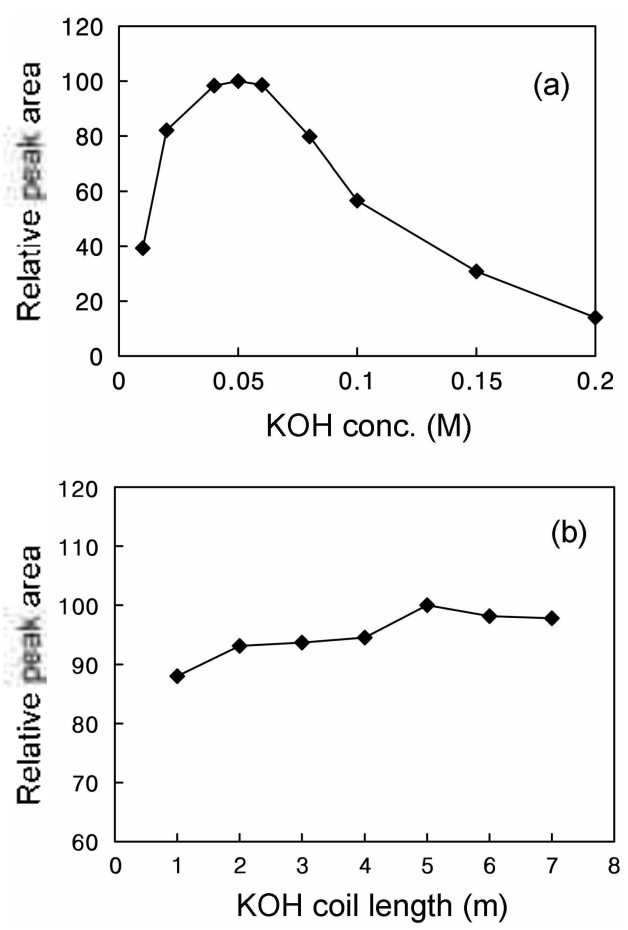

Figure 2. I:Hect of (a) KOH concentration and (b) reaction coil length for KOH on thuoresence intensity: Conditions: $\mathrm{DCAD}$ concentration $0.1 \mathrm{mM}$ : $\mathrm{KOH}$ coil $5 \mathrm{~m}$ : OPA. $20 \mathrm{mM}$. coil. $4 \mathrm{~m}: 0.1$ $\mathrm{M}$ phosphate buller $(\mathrm{pH} 11)$; sullite. $10 \mathrm{mM}$. coil. $4 \mathrm{~m}$ : temperature $60^{\circ} \mathrm{C}$ : mobile phase. 10\% MeOH-0.02 phosphale bullèr (ptl 7). flowrate. $0.5 \mathrm{~mL} / \mathrm{min} ; 100 \mu \mathrm{L}$ injection: fluorescence detector. $\lambda_{\text {ex }}$ $=363 \mathrm{~nm} . \lambda_{\mathrm{em}}=425 \mathrm{~nm}$. sulfite, and $\mathrm{pH}$ were achieved for postcolumn derivatization reaction after composing the RPI.C-postcolumn detection system.

Optimal conditions in postcolumn derivatization reaction Concentration and reaction coil length for $\mathrm{KOH}$. Using a $\mathrm{C}_{18}$ stationary phase, the separated DCAD was mixed with $\mathrm{KOH}$ through the first T-union after passing through a separation column outlet. To find out the optimum conditions for degradation of DCAD into ammonia with $\mathrm{KOH}$, we began with the reaction parameters suggested by Genfa ot al..$^{30}$ and Choi et al ${ }^{\text {11 }}$ These involved the following conditions for postcolumn reaction: $5 \mathrm{~m}, 4 \mathrm{~m}$ and $3 \mathrm{~m}$ for coil 1, coil 2 and coil 3, respectively, $20 \mathrm{mM}$ OPA , $10 \mathrm{mM}$

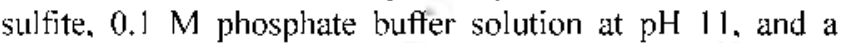
derivatization temperature of $60^{\circ} \mathrm{C}$. In one set of experiments, we varied the concentration of $\mathrm{KOH}$ from $0.01 \mathrm{M}$ to $0.2 \mathrm{M}$, and monitored the peak area for the DCAD derivative by fluorescence detection. As shown in Figure 2a, the relative peak area increased sharply from $0.01 \mathrm{M}$ to $0.05 \mathrm{M}$ and then decreased exponentially up to $0.2 \mathrm{M}$. So, a $0.05 \mathrm{M}$ $\mathrm{KOH}$ was chosen as optimal. While keeping the concentration of $\mathrm{KOH}$ at $0.05 \mathrm{M}$, the reaction coil length for $\mathrm{KOH}$ was varied from $1 \mathrm{~m}$ to $7 \mathrm{~m}$. The highest relative peak area of DCAD derivatives was obtained at $5 \mathrm{~m}$ (Figure 2b). A $0.05 \mathrm{M} \mathrm{KOH}$ solution and a reaction coil length of $5 \mathrm{~m}$ for $\mathrm{KOH}$ were chosen as the optimum condition for DCAD hydrolysis.

Reaction temperature. For the next set of experiments, the concentration of $\mathrm{KOH}$ and its reaction coil length were held at $0.05 \mathrm{M}$ and $5 \mathrm{~m}$, respectively, while other conditions were kept at the baseline conditions as previously described for FlA. We varied the reaction temperature from 30 to $80^{\circ} \mathrm{C}$ and then monitored the peak area for the DCAD derivative as shown in Figure 3. The peak area increased with increasing the temperature, but leveled off at $70^{\circ} \mathrm{C}$. Further increase in temperature led to a decrease in peak area. To diminish baseline noise level caused by the production of water vapor in the tubing at over $50^{\circ} \mathrm{C}$, Genta ot al. ${ }^{30}$ removed the water vapor by inserting porous tubing prior to the fluorescence detector. Instead of using the porous tubing, we found we could substantially reduce the baseline noise

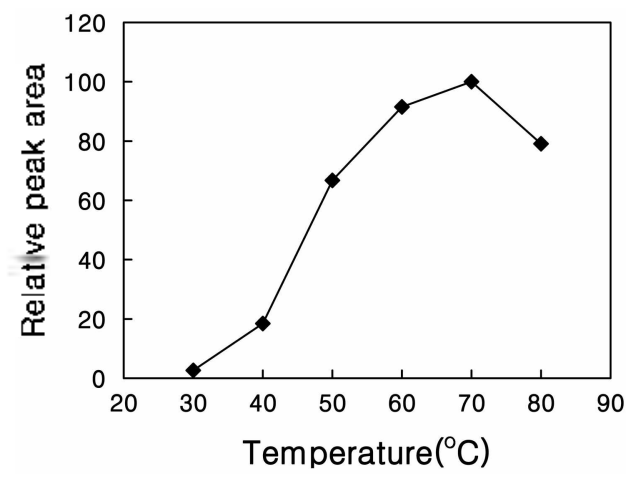

Figure 3. lillect of temperalure on fluorescence intensity. Conditions: the same conditions as in ligure 2 exeept the coil lingth of $0.05 \mathrm{M} \mathrm{KOH}$ was $5 \mathrm{~m}$. 

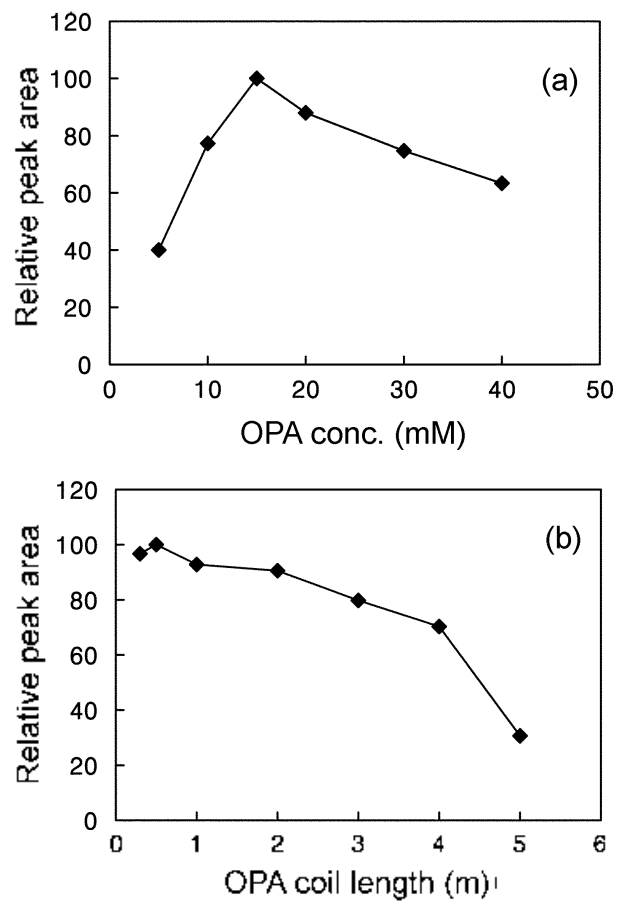

Figure 4. Iflect of (a) OPA concentration and (b) reaction coil length for OPA on fluorescence intensit: Conditions: the same conditions as in Figure 3.

level by insulating the tubing from the water bath to the fluorescence detector. Therefore, the optimum temperature for DCAD base hydrolysis and derivatization reaction was fixed at $70^{\circ} \mathrm{C}$.

Concentration and reaction coil length for OPA. The fluorescence intensity of the DCAD derivative was investigated as a function of concentration and reaction coil length for OPA. The relative peak area of the DCAD derivative increased as the OPA concentration increased up to $15 \mathrm{mM}$. Further increase in the OPA concentration caused a decrease in peak area (Figure $4 a$ ). The reaction coil length was then varied from $0.3 \mathrm{~m}$ to $5 \mathrm{~m}$. The results were shown in Figure $4 \mathrm{~b}$. The maximum peak area was obtained at $0.5 \mathrm{~m}$. The reaction between $\mathrm{OPA}$ and base hydrolyzed DCAD appeared to be nearly instantaneous, so that the shortest possible reaction coil length should be used. The slow decrease in peak area with increasing coil length up to $5 \mathrm{~m}$ was attributed to dispersion effects. Therefore, a $15 \mathrm{mM}$ OPA and a reaction coil length of $5 \mathrm{~m}$ for OPA were chosen as optimal.

Concentration and reaction coil length for Sulfite ion. The sulfite reagent was prepared by dissolving sodium sulfite in $0.1 \mathrm{M}$ phosphate buffer solution. The concentration of sulfite was varied from $5 \mathrm{mM}$ to $20 \mathrm{mM}$. The maximum peak area was obtained at $15 \mathrm{mM}$ (Figure 5a). Further increase in sulfite concentration led to a decrease in peak area. The reaction coil length for sulfite was varied from $1 \mathrm{~m}$ to $7 \mathrm{~m}$. The peak area for the DCAD derivative started to level off at about $3 \mathrm{~m}$ as shown in rigure $5 \mathrm{~b}$. However, the peak area kept increasing slightly up to $6 \mathrm{~m}$. The lack of any variation of relative fluorescence intensity for the DCAD
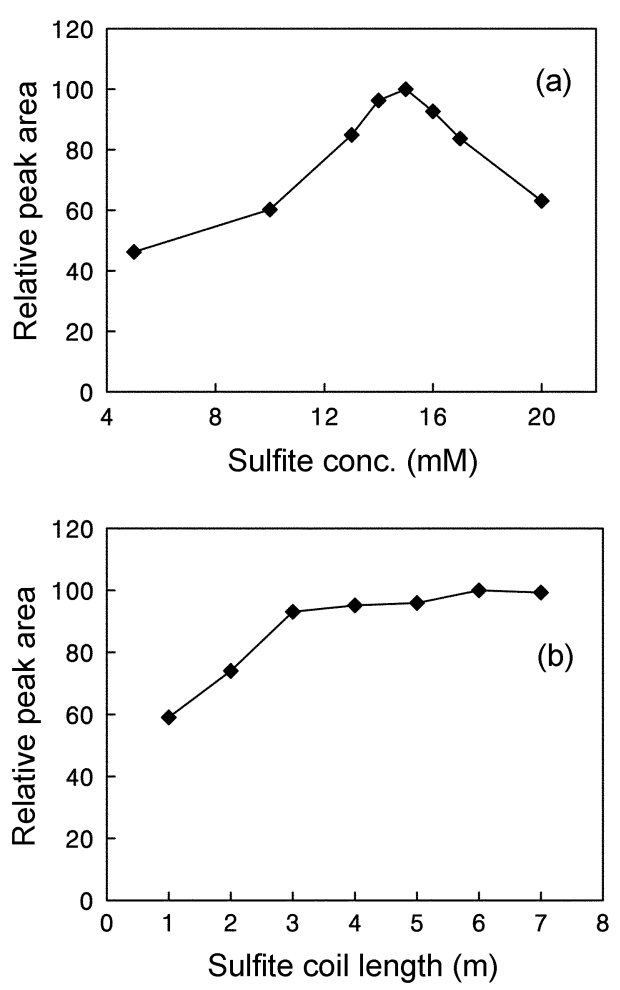

Figure 5. I:fect of (a) suldite concentration and (b) reaction coil length for sulfite on fluorescence intensity. Conditions: the same conditions as in Figure 4 except the reaction coil length of OPA was $0.5 \mathrm{~m}$.

derivative due to any possible oxidative decay of sulfite solution was demonstrated for periods of up to 12 hours as long as the reservoir for the sulfite solution was continuously purged with pure helium gas during analysis. So, a $15 \mathrm{mM}$ concentration of sulfite and a reaction coil length of $6 \mathrm{~m}$ were chosen as optimal.

Reaction pH. In the next set of experiments, we maintained all of the conditions at their optimum values except reaction $\mathrm{pH}$, which was varied from 9 to 13 . The peak area increased dramatically up to $\mathrm{pH} 11.5$, and then decreased rapidly up to $\mathrm{pH} 13$ without any obvious plateau. So, the $\mathrm{pH}$ control in our system was judged as very important. In contrast, Genfa ${ }^{30}$ et $a l$. reported the maximal fluorescence

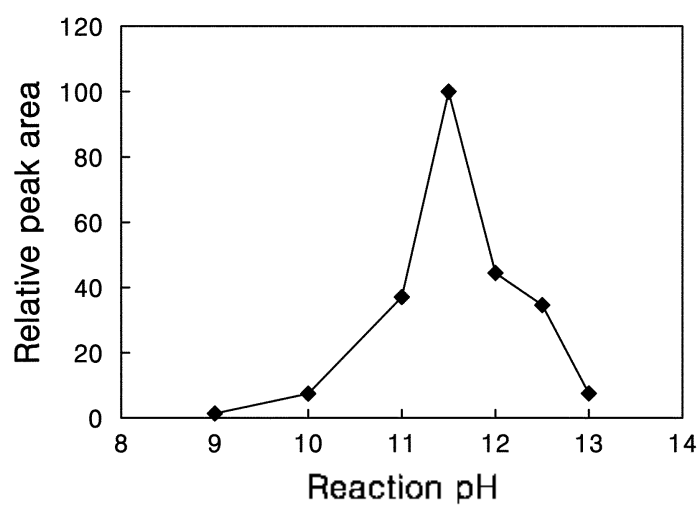

rigure 6. Leffect of reaction pll on fluorescence intensity: Conditions: the same conditions as in Figure 5. 


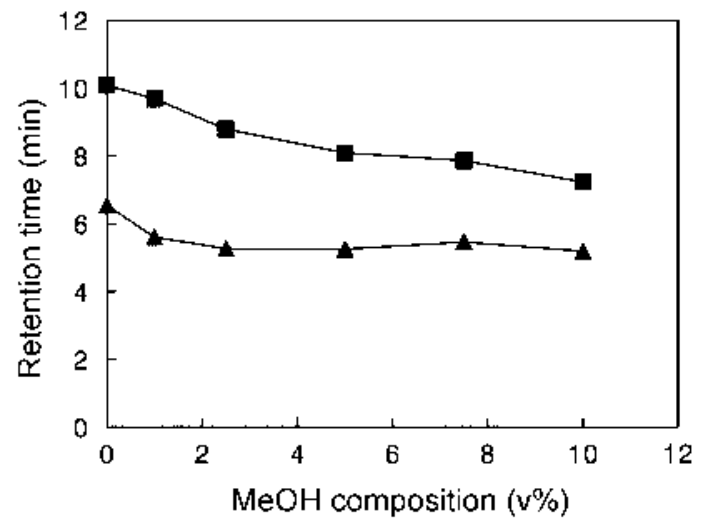

Figure 7. Variation of retention time for $(\boldsymbol{\Delta})$ ammonia and $(\boldsymbol{\square})$ DCAD with $\mathrm{MeOH}$ composition in mobile phase of $0.02 \mathrm{M}$ phosphale buffer al pll 7 on Cis slationary phase. Conditions: DCAD concentration $0.1 \mathrm{mM}$ : KOII. $0.05 \mathrm{M}$. reaction coil. $5 \mathrm{~m}$ : OPA. $15 \mathrm{mM}$. reaction coil. $0.5 \mathrm{~m}$ : sulfits. $15 \mathrm{mM}$. coil. $6 \mathrm{~m}: 0.1 \mathrm{M}$ phosphale buller $(\mathrm{pH} 11.5)$ : temperalure $70^{\circ} \mathrm{C}$ : llow rate, $0.5 \mathrm{~mL}$. min: $100 \mu \mathrm{l}$, injection: lluorescence delector, $\lambda_{\mathrm{m}}=363 \mathrm{~nm}$. $\lambda_{\mathrm{ctn}}=$ $425 \mathrm{~nm}$.

for ammonia/OPA/sulfite derivative at $\mathrm{pH} 11$. It appears that this difference of $0.5 \mathrm{pH}$ unit compared to $\mathrm{pH} 11.5$, obtained from this study, was due to use of $\mathrm{KOH}$ for hydrolyzing DCAD.

Composition and $\mathrm{pH}$ of mobile phase on RPLC. The next set of experiments was aimed at finding the best composition $\mathrm{pH}$ of the mobile phase for separating ammonia and DCAD on a $C_{18}$ nonpolar stationary phase. For this we selected a $0.02 \mathrm{M}$ phosphate buffer solution, because the phosphate salt was used by $\mathrm{Kai}^{3 \cdot 1}$ et al. to analyze peptides, and we considered this to be independent of the choice of the buffer for the postcolumn reaction. The variation of retention time for ammonia and DCAD with $\mathrm{MeOH}$ composition and $\mathrm{pH}$ in mobile phase was investigated on a $\mathrm{C}_{18}$ nonpolar stationary phase under the optimum conditions for postcolumn derivatization obtained from the above experiments. The composition of $\mathrm{MeOH}$ in $0.02 \mathrm{M}$ phosphate buffer solution was varied from $0-10 \%$ at $\mathrm{pH} 7$. As shown in Figure 7 , the retention time $\left(t_{k}\right)$ of ammonia with increasing $\mathrm{MeOH}$ composition kept decreasing up to $2 \%$ and leveled off between at $2 \%$ to $10 \% \mathrm{MeOH}$ composition, whereas those of DCAD kept decreasing up to $10 \% \mathrm{MeOH}$ composition. The relative retention time ( $t_{R}$ of $\mathrm{DCAD} / \mathrm{t}_{\mathrm{R}}$ of ammonia) decreased from 1.54 to 1.39 as the $\mathrm{MeOH}$ mobile phase composition increased up to $10 \%$. Although the plot could not be graphically shown here, maximum peak areas in ammonia and DCAD were found both at $2.5 \% \mathrm{MeOH}$ composition in the mobile phase. Hence, the $\mathrm{MeOH}$ composition was kept at $2.5 \%$, while the $\mathrm{pH}$ of mobile phase was varied from $\mathrm{pH} 2$ to 7 based on the boundary $\mathrm{pH}$ condition for the $\mathrm{C}_{18}$ stationary phase. As shown in Figure 8 , the retention times of both compounds were not approximately affected by the $\mathrm{pH}$ of mobile phase. The relative retention times, $\alpha$ values, of ammonia to DCAD slightly decreased from 2.5 to 1.91 with increasing $\mathrm{pH}$. 'The peak asymmetry factor of ammonia depended on the $\mathrm{pH}$ of mobile phase.

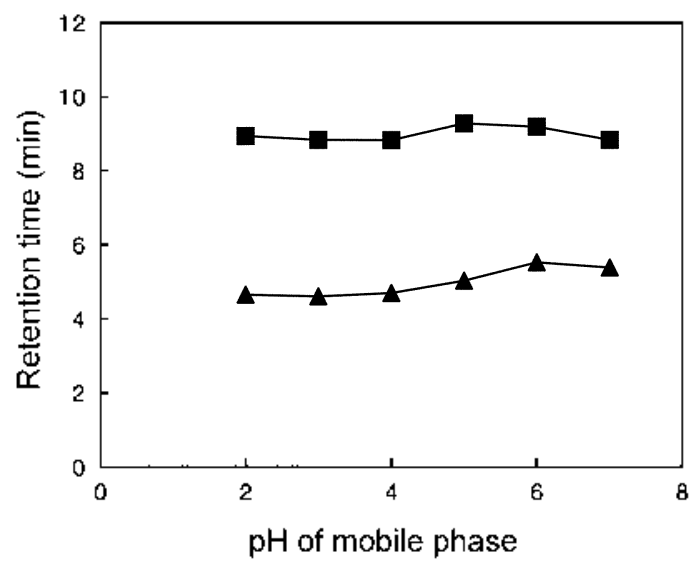

Figure 8. Variation of retention time for ( $\Delta$ ) ammonia and ( $\boldsymbol{\square})$ DCAD with $\mathrm{pH}$ in mobile phase of $2.5 \% \mathrm{McOH}-0.02 \mathrm{M}$ phosphate butler on Cis stationary phase. The optimal conditions for postcolumn derivatiration were the same as in Figure 7.

while that of DCAD was kept nearly constant in the $\mathrm{pH}$ range studied of 2-7. The peak tailing of ammonia was strongly improved with decreasing $\mathrm{pH}$, so that the baseline separation between mixture of ammonia and DCAD was achieved at less than $\mathrm{pH} 3$ of mobile phase. The reason of peak tailing for ammonia on $\mathrm{C}_{18}$ nonpolar stationary phase appeared to be caused by undesirable interaction of ammonia with the residual acidic silanol (Si-OH) groups that were readily accessible to mobile phase on the surface of $C_{18}$ stationary phase. These residual silanol groups were known to cause tailing peak for basic solutes. ${ }^{\text {is }}$ The influence of silanol groups decreased with decreasing $\mathrm{pH}$. This seemed probably due to protonation of silanol group under

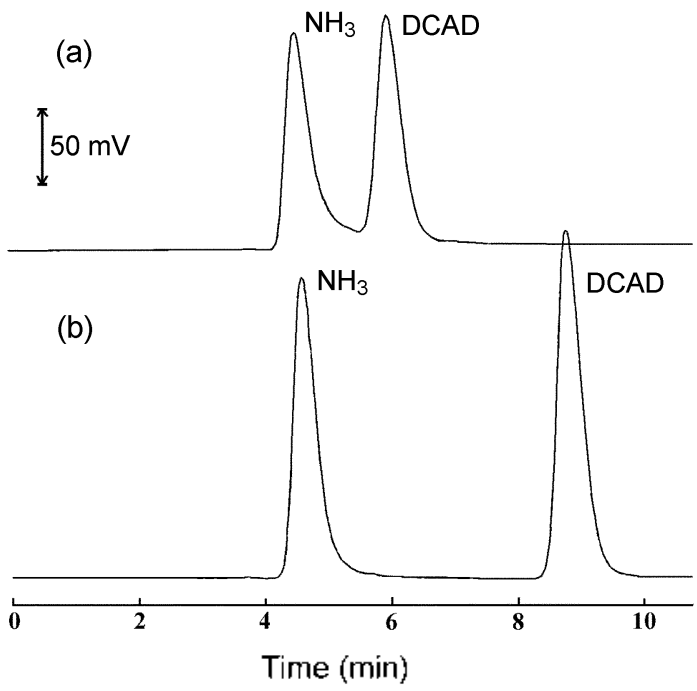

Figure 9. I icjuid chromatogam of ammonia and [)( $\mathrm{ND}$ ) mixlure by RPLC-postcolumn derivatization. Conditions: column. NovaPak $\mathrm{C}_{\mathrm{m}}(3.9 \times 150 \mathrm{~mm})$; (a) $10 \% \mathrm{MLOH}-0.02 \mathrm{M}$ phosphate butfer (pH 7). $0.05 \mathrm{M}$ ammonia. $0.05 \mathrm{~m}$ M DCAD (b) $2.5 \% \mathrm{MeOH}-0.02 \mathrm{M}$ phosphate bullè (phl 3). $0.1 \mathrm{mM}$ ammonia. $0.1 \mathrm{mM}$ I)( AI): flowrate. $0.5 \mathrm{~mL} / \mathrm{min}$ : $100 \mu \mathrm{L}$ injection; $\mathrm{l}$ luoresecence detector. $\lambda_{\text {w }}$ $=363 \mathrm{~nm}$. $\lambda_{\mathrm{em}}=425 \mathrm{~nm}$. Othar postcolumn detection conditions were the same as Figure 6. 
acidic atmosphere of mobile phase. Shown in Figure 9 was the chromatogram of mixture for ammonia and DCAD by RPIC-postcolumn derivatization. A poor resolution between both mixture was observed for a mobile phase of $10 \%$ $\mathrm{MeOH}-0.02 \mathrm{M}$ phosphate buffer at $\mathrm{pH} 7$ (Figure 9a), while a fairly good resolution was observed for a mobile phase of $2.5 \% \mathrm{MeOH}-0.02 \mathrm{M}$ phosphate buffer at $\mathrm{pH} 3$ (Гigure $9 \mathrm{~b}$ ). So, the chromatographic conditions as represented in Figure $9 \mathrm{~b}$ were chosen as optimal and used for all the remaining studies.

Degradation ratio. To find out the degradation yield of DCAD under optimum conditions of RPI.C-postcolumn reaction as established above, the determination for the same concentration of ammonia and DCAD has been achieved by RPI.C-postcolumn derivatization reaction. The degradation yield of DCAD was evaluated by determining DCAD using the standard calibration curve of ammonia in the concentration range of 2-10 $\mu \mathrm{M}$ under the optimum conditions of RPI.C-postcolumn derivatization reaction as established above. The results of the determination for duplicate of 2

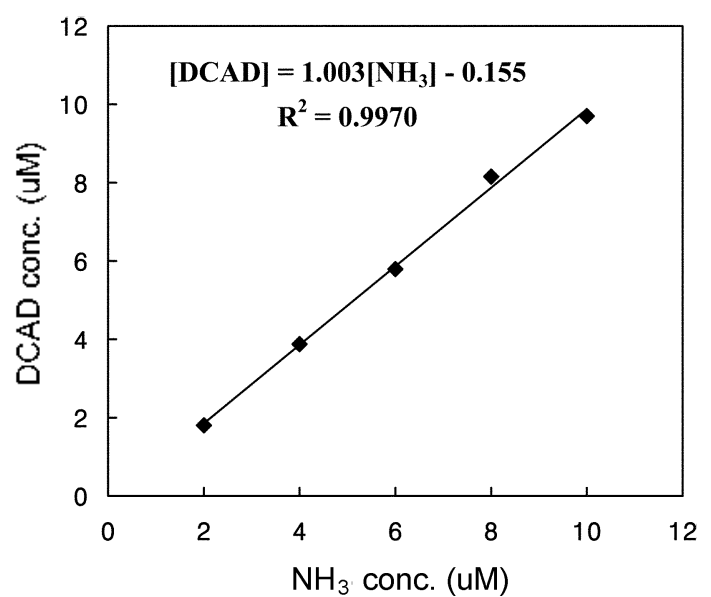

Figure 10. Correlation belween the same concentrations of $\mathrm{NH}_{3}$ and $D(A D)$ by RPLC-postcolumn detection. Conditions: $A$ Il the conditions were the same as in Figure $9 \mathrm{~b}$.

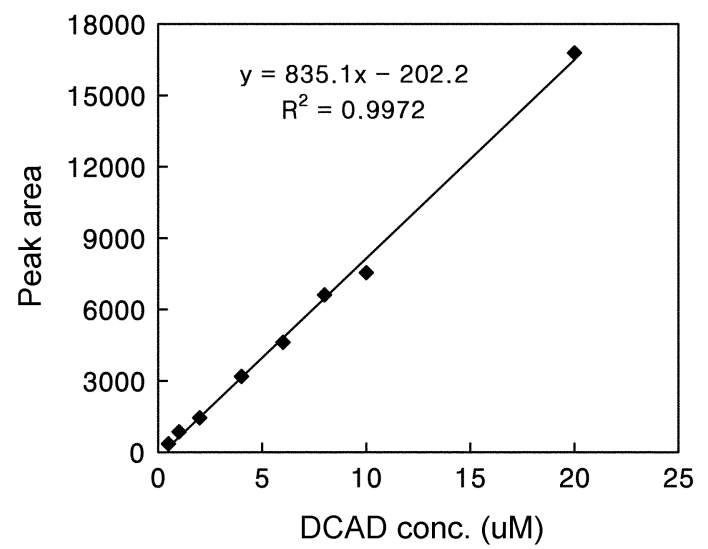

Figure 11. Calibration curve for DCAD by RPLC-postcolumn detection. Conditions: All the conditions were the same as in lïgure 9 b. $\mu \mathrm{M}$ to $10 \mu \mathrm{M}$ DCAD represented that degradation yields for DCAD were $94-99 \%$ in the concentration range studied. It was suggested that DCAD was decomposed into ammonia under the established conditions. A correlation test between concentrations of ammonia and DCAD was carried out in order to show consistency between the compounds. As shown in Figure 10, the result of studying the relationship between the same concentrations of ammonia and DCAD. the concentrations of two substances matched up to $99.7 \%$ with the slope of 1.003 and the coefficient of determination. $\mathrm{R}^{2}$ of 0.9970 . In addition, a paired $t$ test was carried out to decide whether both concentrations were the same or not. The calculated value of $t$ was 1.748 , which was below the value of 2.776 for $95 \%$ confidence and 4 degrees of freedom, ${ }^{36}$ Therefore the two data sets were not significantly different at the $95 \%$ confidence level.

Calibration curve and detection limit. With the optimized conditions as established above, a calibration curve was prepared and found to be linear over the range $0.5-20 \mu \mathrm{M}$ with a following regression equation with the coefficient of determination, $\mathrm{R}^{2}$ of 0.9972 as shown in Figure 11 . The detection limit ${ }^{37.38}$ for DCAD was determined to be $0.18 \mu \mathrm{M}(23 \mu \mathrm{g} / 1)$, which was corresponded to 18 pmol per $100 \mu \mathrm{l}$. injection volume for a signal-to-noise ratio of 3 , and the repeatability and reproducibility of this method were $1.0 \%$ and $2.5 \%$ for five replicate analyzes of $2 \mu \mathrm{M}$ DCAD, respectively.

Regression equation for $\mathrm{DCAD}$ :

Peak area $-835\left[\right.$ DCAD]-202, $\mathrm{R}^{2}-0.9972, \mathrm{n}-8$

Recovery of DCAD in drinking water. To describe the recovery of DCAD in drinking water, the percent recovery of DCAD was calculated by RPI.C-postcolumn detection after filtering through a $0.45 \mu \mathrm{m}$ membrane filter from drinking water spiked at $4-6 \mu \mathrm{M}$. The percent recovery was $97 \pm 5 \%$ at $4 \mu \mathrm{M}$ and $97 \pm 1 \%$ at $6 \mu \mathrm{M}$, both of those were more than $97 \%$.

\section{Conclusion}

The optimum conditions for determining DCAD by RPLC-postcolumn derivatization method were as follows. When ammonia and $\mathrm{DCAD}$ were present at the same time. the baseline separation between peaks for ammonia and DCAD was achieved by minimizing peak tailing of ammonia. The optimum $\mathrm{KOH}$ concentration and reaction coil length for $\mathrm{KOH}$ to measure $\mathrm{DCAD}$ by postcolumn derivatization reaction were $0.05 \mathrm{M}$ and $5 \mathrm{~m}$, respectively. The OPA concentration and its reaction coil were $15 \mathrm{mM}$ and $0.5 \mathrm{~m}$. respectively. The sulfite concentration and its reaction coil length were $15 \mathrm{mM}$ and $6 \mathrm{~m}$. respectively. In addition, the optimal reaction temperature was at $70^{\circ} \mathrm{C}$. and optimal reaction $\mathrm{pH}$ was 11.5 using a $0.1 \mathrm{M}$ phosphate buffer solution. Under these conditions, the degradation ratio of DCAD into ammonia was $94-99 \%$ at $2-10 \mu \mathrm{M}$ and the average recovery was over $97 \%$ in drinking water spiked at 4-6 $\mu \mathrm{M}$. With a signal-to-noise ratio of 3 , the limit of 
detection (LOD) of DCAD was $0.18 \mu \mathrm{M}(23 \mu \mathrm{g} / \mathrm{L})$, which represented 18 pmol when $100 \mu \mathrm{L}$ of DCAD was injected. and the repeatability and reproducibility of this method were $1.0 \%$ and $2.5 \%$ for five replicate analyzes of $2 \mu \mathrm{M} \mathrm{DCAD}$. respectively. The proposed RPLC-postcolumin detection method could be a valuable tool for measuring haloacetamides in drinking water as existing methods (e.g. LLE and GC/ECD) have not been shown to be successful for this group of hydrophilic compounds. It is also attractive because it does not require extraction of the analy tes from water. We also propose that this system can be applied to analyze HANs such as DBAN, DCAN and TCAN for Korean drinking water guidelines, and HAAs as well as HANs simultaneously by slightly modifying to insert UV detector between the separation column outlet and the postcolumn reaction system. The detection linit of this system will be inproved by mounting in-line concentration equipment in near future

\section{References}

1. Glatz. B. A. J.AHTA 1978. $70(8), 465$.

2. Chen. A. M. Science 1980. 207(4), 90

3. Oliver B. G. . AWWA 1983, 17(2).80.

4. Krasner, S. W: McGuire, M. I. Jacangelo. I. G. et al J. AWWA 1989. $80(8), 41$.

5. Singer. P. C. J. EFniron. Engineer 1993, 120.727.

6. Reckhow: D. A.: Singer. P. C. J. AIITA 1984. 76(4). 151.

7. U.S. EPA. Federal register. U.S. EPA. 1994.

8. Ozawa. H. J. Chrontatogr: 1993. 64t. 375 .

9. Terlny, M. L.: Bieber. T. I. Adwatces in the Identification and Anatysis of Orgaric Polhutants in Hater: Keith. L. H.. Ed.: Ann Arbor Science: Ann Arbor. MI. 1981: Vol. 2. p 941.

10. Oliver. B. G. Empiron. Sci. Techmol. 1983, 17(2). 80

11. Yeom, C. M.: Choi, Y. S: Beon. S. J.: Cho. S. H.: Yoon, I. Y. Kor. Soc. Wat Hast 2002. I6(2), 169.

12. Park. S. J.; Pyo, H. S.: Park, S. S. A Stuto on the Anatuticat Hethod and Vational Suneys of Trace Hazardous tompounds in
Drinking Water $\left(5^{\text {th }}\right)$. KAIST Report: Ministry of Environnent: 1997.

13. Yeom. C. M: Choi, Y. S.; Cho, S. H.: Yoon. J. Y. J. Korean Soc. Water Onal. 2003. $19(1), 127$.

14. Lee. K. J.: Hong. J. E.: Pyo. H. S.: Park, S. J.; You. J. G.: Lee. D W. Anal. Sci. Tech 2003. 16(3). 249

15. Park. Y. S. Master degree thesis: Yonsei University. 1996.

16. Kim. J. S. Master degree thesis: Yonsei University: 1996.

17. Alouini. Z.: Seux. R. Wat Res. 1987. 21(3). 335-343.

18. Glezer. V: Harris. B.: Tal, N.: Iosetzon, B.: Lev, O. Wat. Res. $1999,33(8), 1938$.

19. Kezdy. F.: Bruylants. A. Bull. Soc. Chim. Belg. 1960. 69.602

20. Mersaar. U.: Bratt. L. Acta Chem. Scand 1974. A28(7). 715.

21. U.S. EPA Method 551.1. 1995.

22. U.S. EPA Method 552.1990.

23. U.S. EPA Method 552.1, 1992.

24. U.S. EPA Method 552.2, 1992

25. Ko. Y.-W.: Gremm. T. J.: Abbt-Braun. G.: Frimmel. F. H.: Chiang. P.-C. Fresenius J Anal Chem 2000. 366. 244.

26. Magnuson. M. L.: Kelty. C. A. Anal Chem. 2000. $72(10) .2308$

27. Richardson, S. D.: Thruston. A. D.: Caughran, T. V.: Chen, P. H.: Colette, T. W.: Floyd. T. L.; Schenck, K. M.: Lykins. B. W.: Sun. G-R; Majetich, G. Emiront. Sci. Techmol. 1999, 33(19). 3378.

28. Rapp. T.: Reckhow. D. A. manuscript in preparation for submission to Hater Research $\mathbf{2 0 0 4}$

29. Roth. M. Anal. Chem. 1971. f3(7). 880.

30. Genfa, Z.: Dasgupta. P. K. Anal. Chem. 1989, 61. 408.

31. Choi. Y. W. Kim. M. K.: Choi. Y. J. J. Nat. Sci. Res. Inst Jeonin Lniv: 1997. $10(3), 6$.

32. Choi. Y. W. J. Kor Soc. Water Oual 2003. $19(6) .731$.

33. Perrin. D. D.: Dempsey. B. Buffer for pH and Wetal Ion Control. Chapman and Hall: London. 1974: p 156.

34. Kai. M.: Kojima. E.: Ohkura. Y. J. Chromotogr .1 1993, 653. 235.

35. Snyder. L. R.: Kirkland. J. J. Introduction to Hodem Liquid Chrontatograph: $2^{\text {ud }}$ Ed; John Wiley \& Sons, Ine: New York. 1979: pp 272-280.

36. Harris. D. C. Quantitative Analytical Chemistry $4^{\text {th }}$ Ed.: W. H. Freeman and Company: New York. 1995: Chap 4.

37. Chung. Y. S.; Chung, W. S. Bull Korean Chem. Soc. 2003. 2t(12). 1781 .

38. Eskandari, H.; Karkaragh. G. I. Bull. Konean Chem. Soc. 2003. $24(12) .1731$ 